\title{
Key events of pancreas formation are triggered in gut endoderm by ectopic expression of pancreatic regulatory genes
}

\author{
Anne Grapin-Botton, Amit R. Majithia, and Douglas A. Melton ${ }^{1}$ \\ Department of Molecular and Cellular Biology, and Howard Hughes Medical Institute, Harvard University, \\ Cambridge, Massachusetts 02138, USA
}

The mechanisms by which the epithelium of the digestive tract and its associated glands are specified are largely unknown. One clue is that several transcription factors are expressed in specific regions of the endoderm prior to and during organogenesis. Pdx-1, for example, is expressed in the duodenum and pancreas and $P d x-1$ inactivation results in an arrest of pancreatic development after buds formation. Similarly, ngn3 is transiently expressed in the developing pancreas and a knockout results in the absence of endocrine cells. This paper focuses on the question of whether these and other transcription factors, known to be necessary for pancreatic development, are also sufficient to drive a program of pancreatic organogenesis. Using in ovo electroporation of chick embryos, we show that ectopic expression of Pdx-1 or ngn3 causes cells to bud out of the epithelium like pancreatic progenitors. The Pdx-1-expressing cells extinguish markers for other nonpancreatic regions of the endoderm and initiate, but do not complete, pancreatic cytodifferentiation. Ectopic expression of ngn3 is sufficient to turn endodermal cells of any region into endocrine cells that form islets expressing glucagon and somatostatin in the mesenchyme. The results suggest that simple gene combinations could be used in stem cells to achieve specific endodermal tissue differentiation.

[Key Words: Vertebrate; patterning; intestine; stomach; gut; budding]

Received August 28, 2000; revised version accepted December 27, 2000.

Derivatives of the ectoderm, mesoderm, and endoderm give rise to different organs along the antero-posterior axis. It is well established that for the first two germ layers Hox genes play a key role in specifying differentiation and morphogenesis along this body axis (McGinnis and Krumlauf 1992; Lumsden and Krumlauf 1996). A few upstream regulators of Hox genes and numerous downstream targets have been identified. Comparable information is largely absent for the endoderm layer that forms the gut epithelium and contributes to many digestive and nondigestive glands. Some transcription factors are expressed in specific regions of the endoderm prior to organogenesis when it is a cuboidal epithelium that progressively forms a tube. We have previously mapped on serial sections the relative expression domains of several transcription factors in presumptive endodermal territories of different organs (Grapin-Botton and Melton 2000). Two questions emerge from this map: (1) How is the expression of different genes restricted to specific endodermal regions? (2) How are they involved in organogenesis? Here, we investigate the second question, focusing on the region that forms the pancreas.

${ }^{1}$ Corresponding author.

E-MAIL dmelton@biohp.harvard.edu; FAX (617) 495-8557.

Article and publication are at www.genesdev.org/cgi/doi/10.1101/ gad. 846001.
The pancreas forms in the region of the duodenum immediately posterior to the stomach. After the formation of the gut tube, dorsal and ventral pancreatic buds that will later fuse grow from the endodermal epithelium that is surrounded by mesenchyme. Some cells in the bud differentiate into exocrine cells that retain epithelial characteristics and form branched ducts and acini. Endocrine cells emigrate from the epithelium and aggregate into islets within the mesenchyme. Several studies point to the importance of mesenchymal signals in pancreas ontogeny, but more is known about the transcriptional regulation within endodermal cells (Edlund 1998; Fig. 1).

Many pancreatic transcription factors have been inactivated by homologous recombination in the mouse, but two genes are of particular interest because of their early effects. The homeodomain protein b9 (Hlxb-9) is required for dorsal, but not ventral, bud initiation (Harrison et al.et al. 1999; Li et al. 1999|. Pancreas-duodenumhomeodomain protein $(\mathrm{Pdx}-1)$ is required for bud expansion but the initiation of bud formation appears normal in homozygous mutant mice for this gene (Jonsson et al. 1994; Offield et al. 1996). The molecular determinants that define the position of buds and the localized expression of Hlxb-9 and Pdx-1 in the endoderm are currently unknown. 


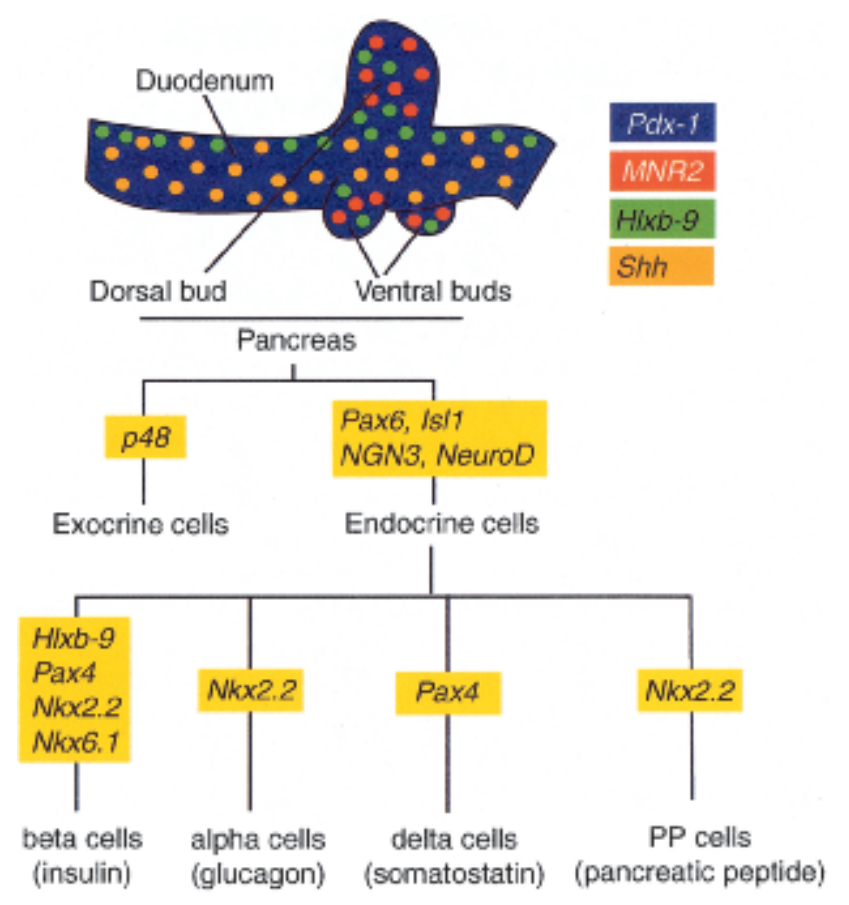

Figure 1. Genes involved in pancreas organogenesis. Expression domains of $H 1 x b-9, P d x-1$, Shh and MNR2 in the duodenopancreatic region of the E4 chick embryo are color encoded (Kim et al. 1997b; A. Grapin-Botton, unpubl.). Expression domains of the three first genes are similar in the mouse at E10.5 (Echelard et al. 1993; Jonsson et al. 1994; Offield et al. 1996; Apelqvist et al. 1997; Harrison et al. 1999; Li et al. 1999). An MNR2 homolog has not yet been identified in the mouse. A flow chart shows transcription factor involvement in the differentiation of pancreatic cell types as interpreted from expression and inactivation data in the mouse (Ahlgren et al., 1997; Naya et al. 1997; Sander et al. 1997; Sosa-Pineda et al. 1997; St-Onge et al. 1997; Sussel et al. 1998; Gradwohl et al. 2000; Krapp et al. 1998).

After bud formation, several transcription factors have been shown to be required for the differentiation of specific cell types (Fig. 1). Paired homeodomain proteins Pax4 (Sosa-Pineda et al. 1997) and Pax6 (Sander et al. 1997; St-Onge et al. 1997), LIM homeodomain protein islet-1 (isl1) (Ahlgren et al. 1997), Nkx6.1 and Nkx2.2 (Sussel et al. 1998), Hlxb-9 (Harrison et al. 1999; Li et al. 1999) as well as the basic helix-loop-helix (bHLH) proteins NeuroD (Naya et al. 1997) and neurogenin 3 (ngn3; Gradwohl et al. 2000) are necessary for the differentiation of all or a subset of the four endocrine cell types (Fig. 1). The bHLH protein PTF1-p48 is required for the differentiation of exocrine cells (Krapp et al. 1998). Although these transcription factors are required for pancreatic organogenesis, it is not understood how they are turned on, whether they function in a common pathway or whether they are sufficient for a particular aspect of pancreatic organogenesis.

As one approach to these issues, we have ectopically expressed pancreatic genes in other regions of the endoderm. We put some emphasis on $P d x-1$, a gene that is thought to be a major player of pancreas formation, be- cause it is one of the first genes expressed in the presumptive territory of the pancreas and because of the early effect of its inactivation. Our results show that although $P d x-1$ is able to initiate features of pancreatic development, including patterning and morphogenetic events in endodermal cells outside the pancreas field, it is not sufficient to trigger complete exocrine or endocrine cell differentiation. Pdx-1 induces cell budding from the epithelium, down-regulates the expression of genes $(C d x A, c d x C$, Sox2, Hex, and $S h h)$ that are characteristic of adjacent regions of the endoderm and activates the $\beta$-cell marker Hlxb-9. Other pathways of gene activation or inactivation are evidently required to drive complete pancreatic cell differentiation.

Two recent studies have identified ngn3 as a potential initiator of endocrine differentiation. ngn3 is transiently expressed in a subset of pancreatic cells, and its inactivation prevents differentiation of all endocrine cells in the pancreas (Gradwohl et al. 2000). In addition, constitutive activation throughout the pancreas anlage results in an increase and precocious differentiation of glucagonproducing $\alpha$ cells (Apelqvist et al. 1999; Schwitzgebel et al. 2000). The activation of upstream activators of ngn3 results in the same effect (Apelqvist et al. 1999) as well as the inactivation of negative regulators (Jensen et al. 2000). Therefore, we ectopically expressed ngn3 and found that it is sufficient to turn epithelial cells from all levels along the antero-posterior axis of the gut into glucagon- and somatostatin-producing cells. Moreover, ngn3-expressing cells leave the epithelial layer and form islets within the mesenchyme.

\section{Results}

\section{Pdx-1 elicits cell budding from the gut epithelium}

To test whether Pdx-1 is sufficient for the initiation of pancreatic development, we misexpressed this gene in a domain that is wider than its normal expression domain by use of in ovo electroporation (Fig. 2). Embryos were electroporated at stage 13-15 of Hamburger and Hamilton $(\mathrm{HH}$; Hamburger and Hamilton 1951), which is shortly after the onset of $P d x-1$ endogenous expression. Embryos were analyzed $48 \mathrm{~h}$ later, when the dorsal and ventral pancreatic buds are first visible, or $72 \mathrm{~h}$ later when the pancreas has begun to show a branched epithelium. The in ovo electroporation procedure we used targets only the endoderm; mesodermal cells never express transgenes in these conditions (Fig. 3A,B).

Cells overexpressing $P d x-1$ lose the elongated shape characteristic of columnar epithelia within $48 \mathrm{~h}$ after electroporation. After $72 \mathrm{~h}$, about $70 \%$ of the cells expressing high levels of $P d x-1$ migrate out of the gut epithelium into the mesenchyme, and occasionally into the lumen (Fig. 3D,E). Electroporated cells that express lower levels of $P d x-1$, as assessed by in situ hybridization, remain in the epithelium. The budding is observed everywhere in the targeted region, from the esophagus to the yolk stalk. Clumps of electroporated cells resemble pancreatic buds, remaining associated together and, 
Figure 2. In ovo electroporation of the chick endoderm. Electroporation is carried out in two steps schematized here in sagittal sections of the egg (left) and transverse sections of the embryo (right). The position of the transverse section is shown with a red doubleheaded arrow on the egg. The DNA solution is shown in blue. Electroporated genes are boxed.
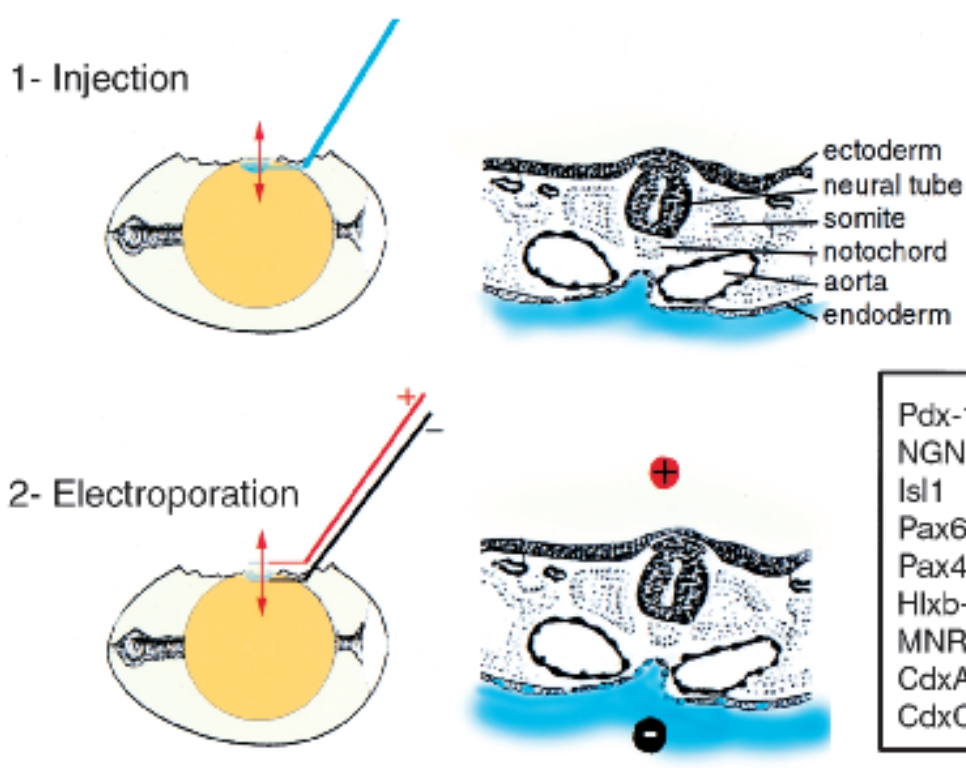

$\mathrm{Pdx}-1$ NGN3 Isl1 Pax6 Pax4 Hlxb-9 MNR2

$\mathrm{CdxA}$ $\mathrm{CdxC}$ most of the time, connected to the epithelium (Fig. 3E). Individual cells also migrate and are sometimes found as far as 20 mesenchymal-cell-diameters away from the epithelium. The ability to change shape and emigrate from the epithelium is not observed when a plasmid encoding a mutated form of Pdx-1, unable to bind DNA, is electroporated instead (Fig. 3C) or when a plasmid expressing a closely related homeobox gene $(C d x A)$ is electroporated (Fig. 3F).

A pancreas does not bud when $H l_{x} b-9$ is inactivated, so we tested whether this gene is capable of eliciting bud formation. Unlike $P d x$-1-positive cells, Hlxb-9 overexpressing cells do not delaminate and migrate into the mesenchyme (Fig. 3G). Occasionally, some Hlxb-9-ex-
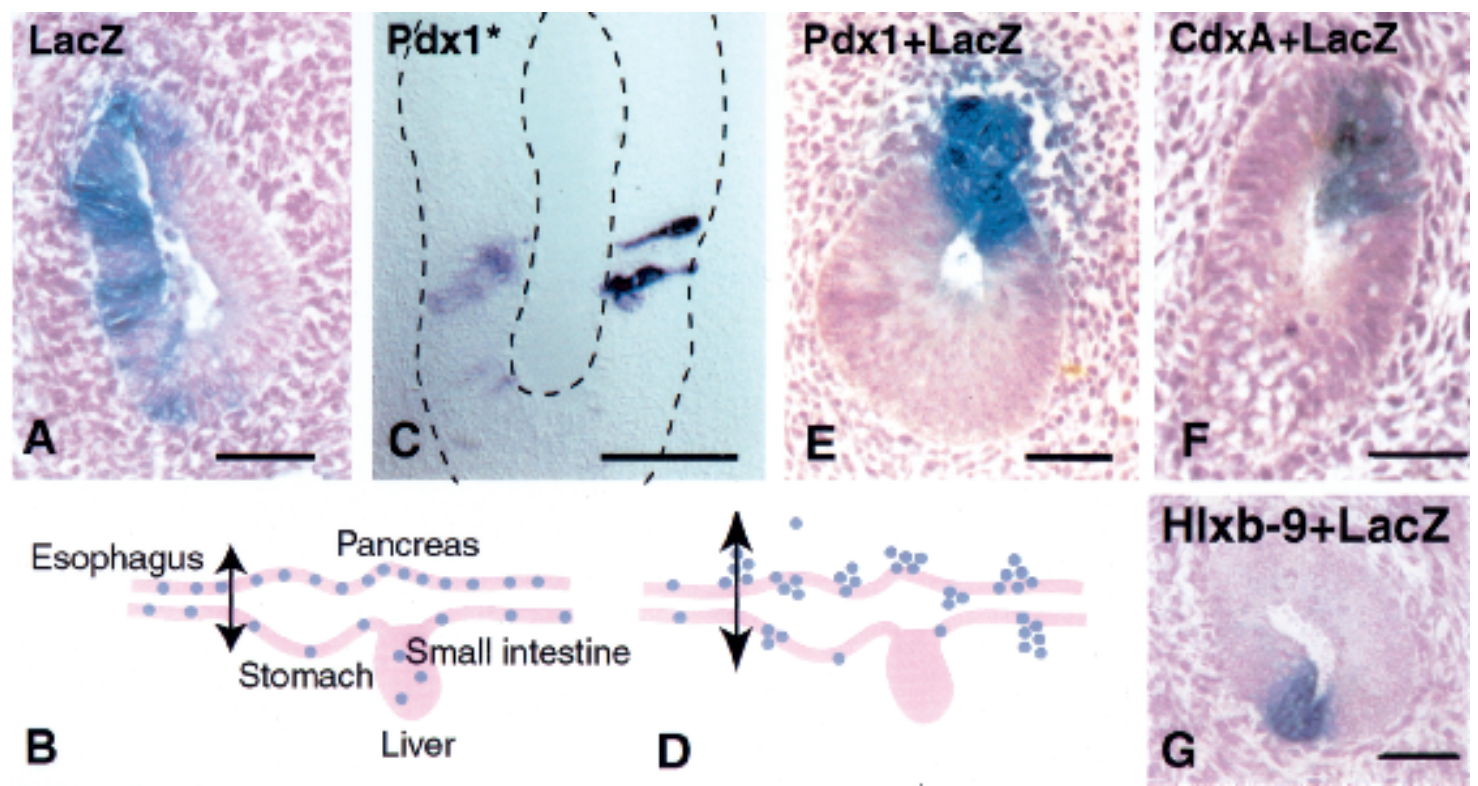

Figure 3. $\quad P d x-1$ induces bud formation. Endoderm cells electroporated with a LacZ-expressing construct always reside in the endodermally derived epithelial layer of the gut as shown in a transverse section at the level of the esophagus in $(A)$. LacZ-positive cells are never observed in the mesodermally derived mesenchyme. (B) Electroporated cells are spread out from the level of the stomach down to at least the yolk stalk in the small intestine. When cells are electroporated with the LacZ-expressing construct together with a $P d x$-1-expressing vector, cells bud out of the epithelial layer $72 \mathrm{~h}$ after electroporation as shown in $E$ and $D$. Endoderm cells electroporated with a mutated form of Pdx-1 that cannot bind DNA (Pdx-1*) remain in the epithelium and keep a columnar shape, as shown in $C$ after in situ hybridization for $P d x$-1. When cells are electroporated with the LacZ-expressing construct together with a plasmid expressing $C d x A(F)$ or a $H 1 x b-9(G)$, they stay in the epithelial layer $72 \mathrm{~h}$ after electroporation. Bars, $50 \mu \mathrm{m}$. 
pressing cells are observed in clumps in the lumen of the gut.

Ectopic Pdx-1 expression turns off markers of the posterior small intestine, stomach, and liver

In addition to the morphological changes induced by ectopic $P d x-1$ expression, we tested for effects on molecular markers of regional patterning within the endoderm. As shown in Figure 4, several transcription factors are expressed in specific regions of the endoderm prior to organogenesis, from the beginning of somitogenesis. These expression domains, existing endoderm fate maps, and the later organ-specific expression lead to the suggestion that these genes mark prospective organ territories. The antral stomach and regions more anterior all express Sox2. The duodenum, posterior stomach, and pancreatic region express $P d x-1$; the small and large intestine posterior to the duodenum express $C d x A$; the duodenum, pancreas, and small intestine express $C d x C$; and the liver, bile duct, and thyroid gland express Hex.
The boundaries between expression domains are graded rather than sharp. The $P d x-1$ expression domain is limited anteriorly by Sox 2 and posteriorly by $C d x A$ expression domains and stops at the beginning of the bile duct where Hex begins expression. $C d x C$ is expressed at low levels in the same domain as $P d x-1$ and at higher levels more posteriorly. MNR2 is specifically and ubiquitously expressed in the pancreatic buds within the endoderm.

The expression of these markers was analyzed $48 \mathrm{~h}$ after electroporation of $P d x-1$, before the cells migrate from the epithelium. $P d x-1$ ectopic expression in the esophagus and anterior stomach leads to Sox2 downregulation (Fig. 4). $P d x-1$ expression in the small intestine between the duodenum and yolk stalk turns $C d x A$ off (Fig. 4), down-regulates $C d x C$, and turns off $H e x$ in the bile duct (Fig. 4). Ectopic Pdx-1-expressing cells thus lose their original molecular identity. This finding is consistent with the fact that $P d x-1$ is never colocalized in normal embryos with these other regional markers (except for low levels of $C d x C$ ). However, the effect is not reciprocal: neither $C d x A$ nor $C d x C$ down-regulates
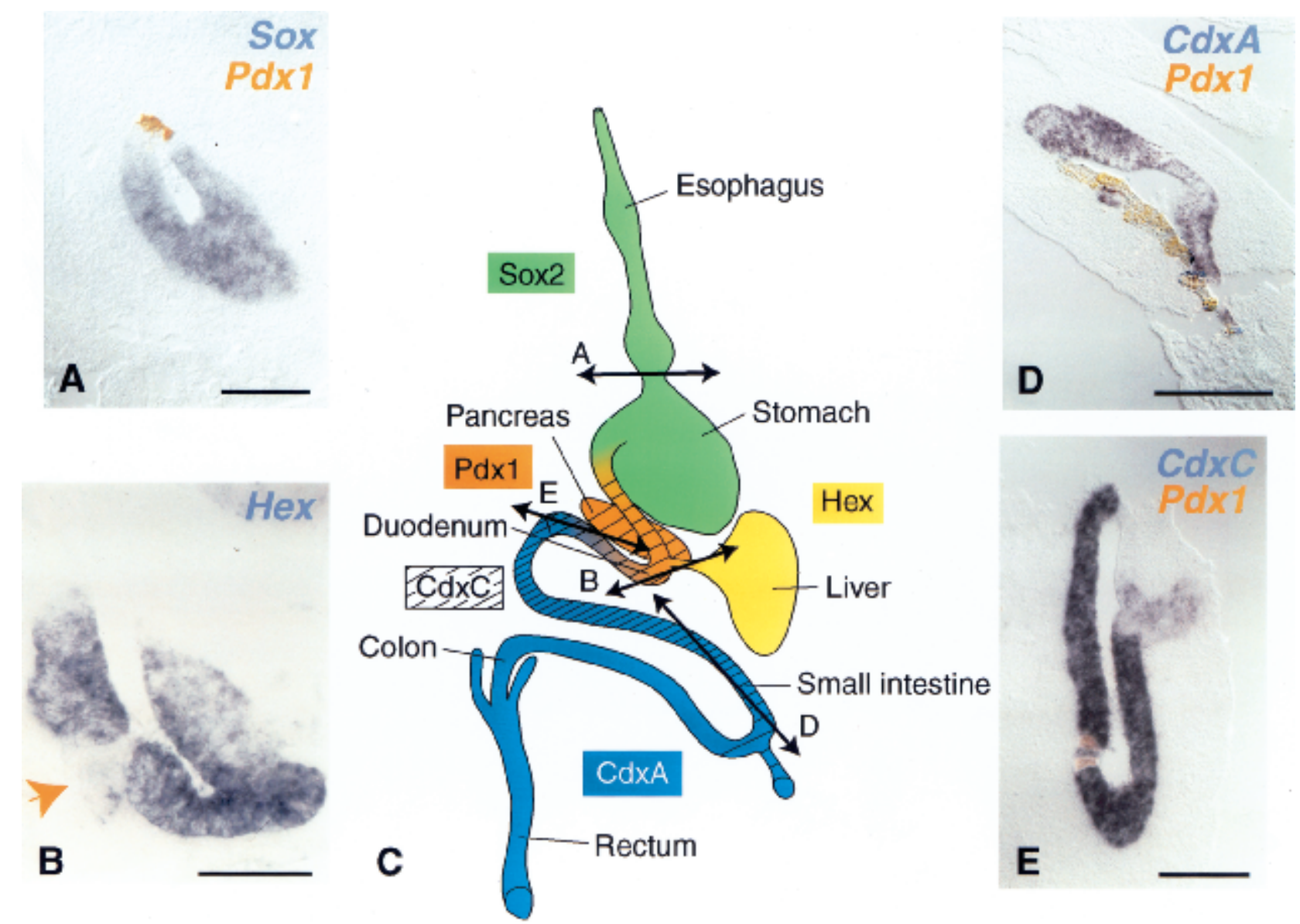

Figure 4. $P d x-1$ turns off the expression of markers of regions adjacent to the duodenum. Double in situ hybridization with $P d x-1$ in orange $(A, B, D, E)$ and Sox2 in the stomach $(A), \operatorname{Hex}$ in the bile duct $(B), C d x C(D)$ and $C d x A$ in the jejunum $(E)$ in blue shows that expression of the latter is either turned off $(A, B, E)$ or down-regulated $(D)$ by ectopically expressed Pdx-1. $(C)$ Sites of normal genes expression. In $B, P d x-1$ expression was monitored on adjacent sections (not shown) and occurred where indicated (arrow) in a group of cells leaving the bile duct epithelium. The locations of sections $A, B, D$, and $E$ are shown in $C$. Bars, $50 \mu \mathrm{m}(B), 100 \mu \mathrm{m}(A), 200 \mu \mathrm{m}$ $(D, E)$. 
$P d x-1$ when ectopically expressed in the duodenum (data not shown).

In addition to these transcription factors, the signaling molecule Sonic Hedgehog (Shh) is expressed in most of the gut epithelium posterior to the esophagus with the exception of the pancreas, liver, and bile duct. Correspondingly, ectopic Pdx-1 expression leads to Shh downregulation (Fig. 5). Ectopic expression of $M N R 2$, a pancreas bud marker, or Hlxb-9, a dorsal gut tube and pancreatic bud marker, also turns off Shh (Fig. 5). MNR-2 and, to a lesser extent, Hlxb-9 up-regulate each other, but neither is able to induce $P d x-1$ (data not shown). None of the transcriptional effects (down-regulations) described above is mimicked by a mutated form of Pdx-1, engineered to be incapable of binding DNA /data not shown). Additional evidence for specificity is provided by use of the homeobox gene $C d x A$, which is closely related to $P d x-1$. Unlike $P d x-1, C d x A$ does not downregulate $C d x C$ or Sox2 (data not shown). Taken together,
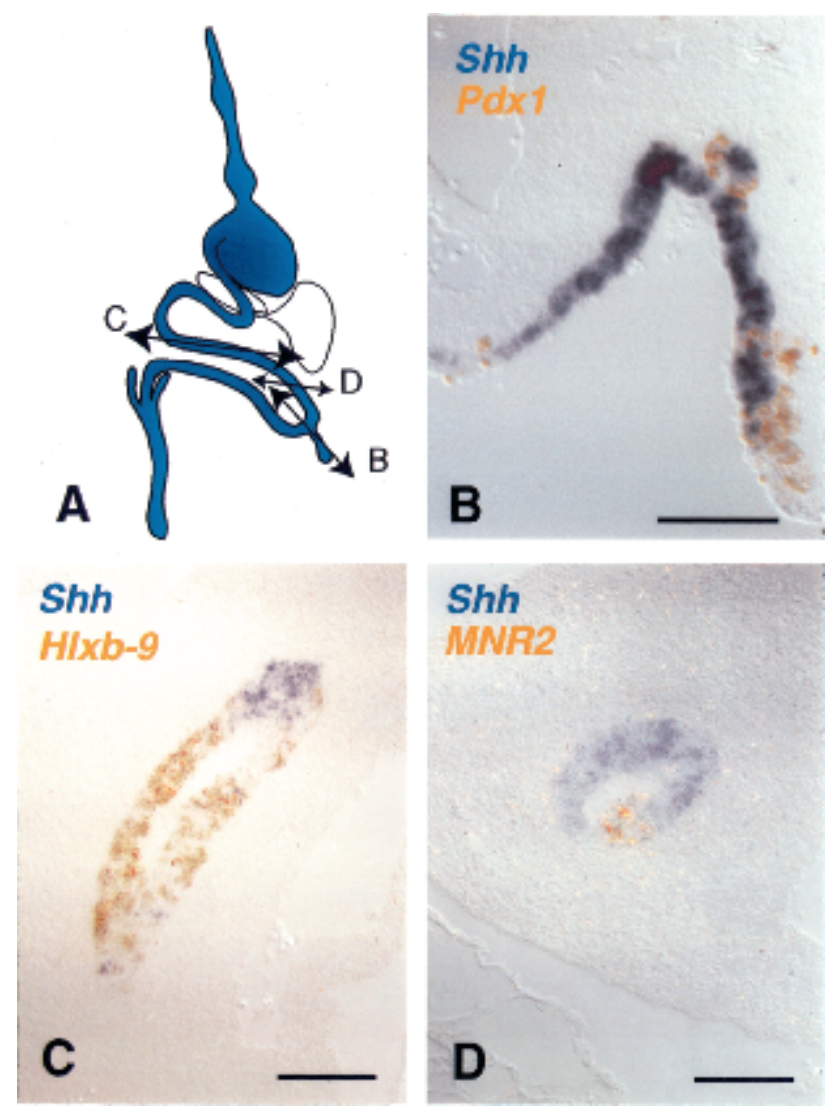

Figure 5. $P d x-1, H 1 x b-9$, and MNR2 turn off Shh expression. (A) Shh is normally expressed in the gut tube epithelium but not in the pancreas, liver, and bile duct. $(B)$ Double in situ hybridization for misexpressed $P d x-1$ (orange) and Shh (blue) shows that $P d x$-1-expressing cells in the intestine cease expressing Shh. (C) Double in situ hybridization for misexpressed Hlxb-9 (orange) and Shh (blue) shows that Hlxb-9-expressing cells in the intestine cease expressing Shh. (D) Double in situ hybridization for misexpressed MNR2 (orange) and Shh (blue) shows that MNR2-expressing cells in the intestine cease expressing Shh. Bars, $100 \mu \mathrm{m}$. the loss of marker expression following Pdx-1 electroporation suggests that these cells acquire a pancreatic bud identity. Therefore, we tested whether $P d x-1$-expressing cells acquire the ability to complete a pancreatic program of cytodifferentiation.

\section{Pdx-1 is sufficient for initiating, but not completing, endocrine cell differentiation}

Cells of the pancreatic buds differentiate into four endocrine cell types, ductal cells, and exocrine cells. RNA transcripts for the two major endocrine hormones, glucagon and insulin, are first detected at stage HH15 and HH16 respectively (Kim et al. 1997). Glucagon protein is first detected at stage $\mathrm{HH} 16-\mathrm{HH} 17$ (Beaupain and Dieterlen-Lièvre 1974; Sumiya and Mizuno 1987) and insulin protein at stage HH19. The exocrine marker carboxypeptidase A is detected later, at stage HH19 (E3.5) by PCR and immunocytochemistry. Pdx-1-overexpressing cells never fully differentiate into endocrine or exocrine cells as evidenced by their inability to express insulin, glucagon, or carboxypeptidase A at 48, 72 or $96 \mathrm{~h}$ after electroporation. These time points represent days after the normal expression of the markers. Moreover, the $P d x-1$ expressing cells do not turn on other earlier markers of endocrine differentiation such as Pax6, is11, or Nkx2.2 (Fig. 1; data not shown).

However, these cells do progress to the point of turning on $H l_{x} b-9$. Hlxb-9 is a marker expressed in the dorsal gut tube, a subset of cells of the early pancreatic bud and is later restricted to the $\beta$-cell lineage. About half of the cells expressing $P d x-1$ also express $H 1 x b-9$ at 24 and $48 \mathrm{~h}$ post electroporation (Fig. 6). The absence of $H 1 \mathrm{xb}-9,72 \mathrm{~h}$ after electroporation (data not shown) suggests that either the differentiation program aborts or that the cells expressing $H 1 x b-9$ die. Interestingly, $M N R 2$, a homeobox gene that is very similar to Hlxb-9 (Tanabe et al. 1998) and that is homogeneously expressed in pancreatic buds (data not shown), is not induced by $P d x-1$ (Fig. 6). As a control, Hlxb-9 is not induced in cells expressing the mutated form of $P d x-1$, whose product is unable to bind DNA (data not shown). Taken together these data suggest that the $P d x$-1-expressing cells initiate a program of pancreatic development but do not proceed to a final stage of cytodifferentiation.

We hypothesized that additional transcription factors, perhaps those activated by signaling molecules only present in the pancreas region, are missing and, therefore, the electroporated cells cannot fully differentiate. Thus, we expressed three other transcription factors, each required for differentiation of endocrine lineages, along with Pdx-1: Pax6, Is11, and ngn3 (Fig. 1). Neither Pax6 plus Pdx-1 nor Isl1 plus Pdx-1 elicited insulin or glucagon expression (data not shown). Co-expression of Pdx-1 and ngn 3 did produce further differentiation.

\section{ngn3 induces glucagon/somatostin islet formation}

Electroporation of plasmids encoding both Pdx-1 and ngn3 or ngn3 alone drives cells to all differentiate into 


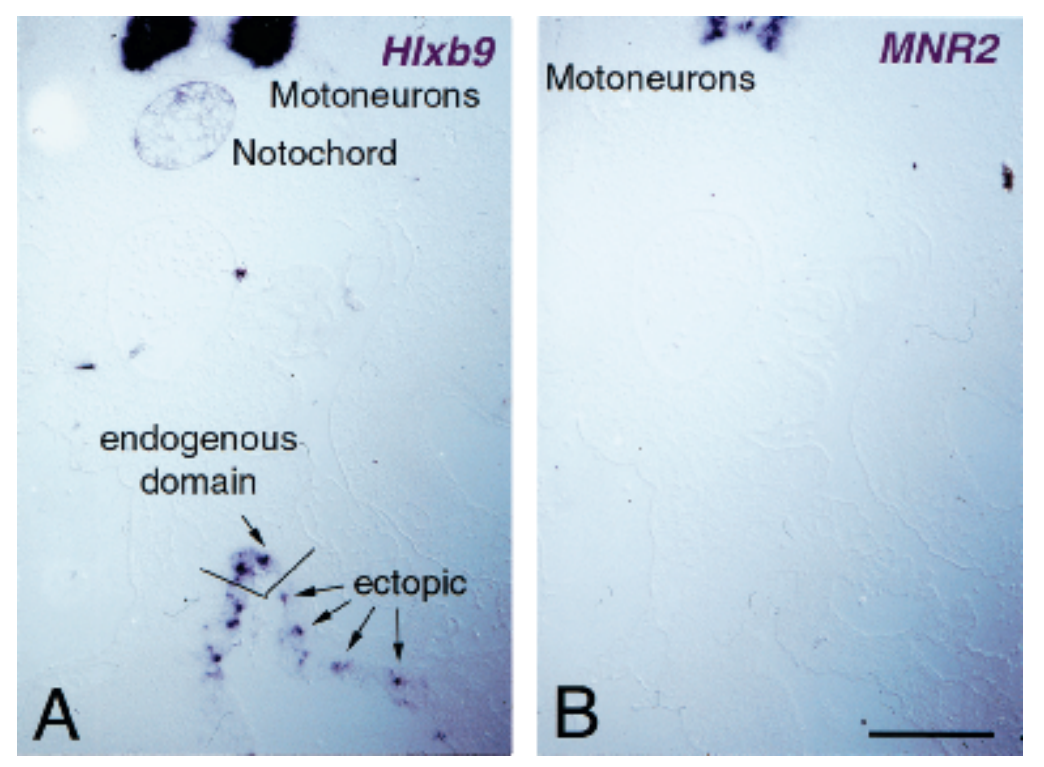

Ectopic expression of pancreatic regulatory genes
Figure 6. $P d x-1$ initiates pancreatic differentiation in gut epithelium. (A) The expression of the transcription factor $H 1 x b-9$, normally restricted to the most dorsal part of the gut epithelium, underneath the notochord, is induced by Pdx-1, as evidenced by in situ hybridization on a transverse section of the intestine at the level of the yolk stalk. Its endogenous expression domains in the notochord and motoneurons are shown in the upper part of the photograph. $(B)$ The related transcription factor MNR2 is not evidenced in the gut on an adjacent section. (Top) MNR2 expression in motoneurons. Bar, $100 \mu \mathrm{m}$. endocrine cells, $48 \mathrm{~h}$ after electroporation. This occurs in all targeted regions, from the esophagus to the yolk stalk, including the pancreas. Glucagon is found in a majority of cases whereas somatostatin expression is less prevalent (in about $10 \%$ of the cells; Fig. 7). Neither insulin nor pancreatic peptide production is observed, 48 or $72 \mathrm{~h}$ after electroporation (Fig. 7) a time when insulin is normally expressed in the pancreas (Kim et al. 1997). Fortyeight hours after electroporation, 90\% of ngn3-misexpressing cells are found in the mesenchyme, outside the epithelium in groups of 10 to 100 cells. In these aggregates, glucagon and somatostatin are expressed in different cells with a reproducible arrangement: glucagon cells in the middle and somatostatin cells at the periphery (Fig. 7G-J). Groups of cells are sometimes observed in the lumen of the gut tube. The fact that cells receiving ngn3 bud out one day earlier than $P d x-1$ misexpressing cells suggests that the two genes have different effects.

Additional endocrine cell markers, Pax6, is11, NeuroD, and $N k x 2.2$ (Fig. 1), are ectopically induced by ngn3 (data not shown) providing further evidence for a difference between $P d x-1$ and $n g n 3$ ectopic expression. $P d x-1$ is not induced by ngn3 (data not shown). Hlxb-9, a marker for $\beta$ cells of the pancreas and a few dorsal cells of the gut tube, is found in a subset of ngn3-overexpressing cells outside its normal expression domain (data not shown).

ngn3 is required for differentiation of all pancreatic endocrine lineages in mice (Gradwohl et al. 2000) but when expressed alone, before the formation of the bud, under the control of the $P d x-1$ promoter, it does not induce insulin-cell differentiation (Apelqvist et al. 1999; Schwitzgebel et al. 2000 ). During normal development, glucagon cells appear before insulin cells and ngn3 is expressed throughout this period of pancreatic development. To test whether ngn3 produces glucagon cells, and not insulin cells, because of the time at which the gene is expressed, the electroporations were also performed at a stage (HH18) after insulin producing cells have begun to appear. However, as with electroporations at stages $\mathrm{HH} 13$ and HH15, this later time point produces glucagon, but not insulin, cells in the small intestine.

All endocrine cell types are thought to derive from common precursors that subsequently commit to specific lineages (Alpert et al. 1988). On the basis of targeted mutations in mice, Pax 4 has been proposed to control the commitment from $\alpha$ cells (glucagon) to $\beta$ cells (insulin; Sosa-Pineda et al. 1997). When tested by electroporation, Pax4 and ngn 3 trigger only glucagon and not insulin expression (data not shown).

\section{Discussion}

In the emerging era of large-scale analysis of gene function, three questions relevant to organogenesis are essential: (1) What is the panel of genes expressed in the organ?; (2) For what steps of organ formation are they required?; (3) How are they connected one another? As far as the pancreas is concerned, the expression of a wealth of transcription factors has already been demonstrated. In addition, many of them have been knocked out by homologous recombination which allows for a classification into genes that are important for either the budding of the gland or differentiation of endocrine or exocrine cells. We have adapted a quick method to determine whether these genes are sufficient for certain aspects of organogenesis.

\section{Pdx-1 is sufficient to induce bud formation}

The $P d x-1$ gene is expressed in the duodenum and pancreas bud and in their prospective endodermal regions (Jonsson et al. 1994; Offield et al. 1996). $P d x-1$ is restricted to $\beta$ cells that produce insulin. When $P d x-1$ is inactivated, the pancreas bud is initiated and a few glu- 


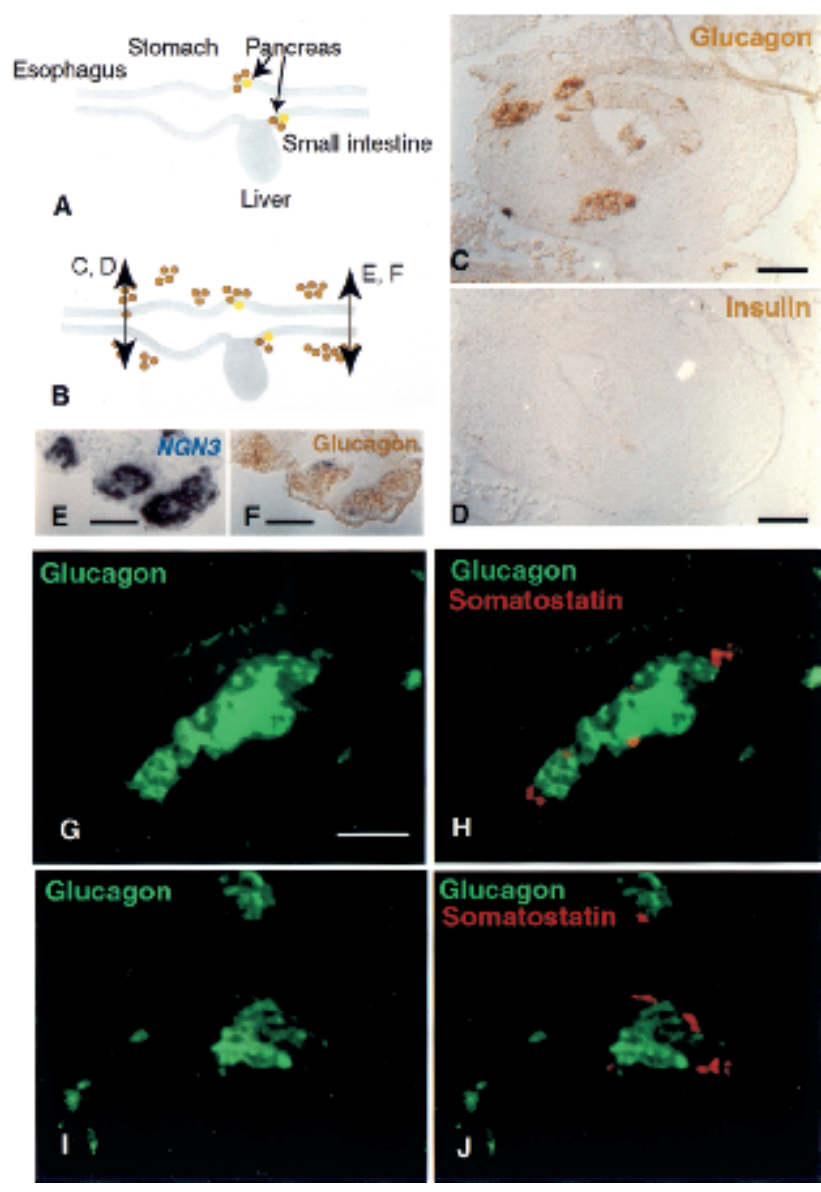

Figure 7. ngn3 induces glucagon- and somatostatin-islet formation from the esophagus to the yolk stalk. $(A)$ Glucagon (brown) and insulin (yellow) are synthesized in cells of the E4 pancreatic buds but not in other cells of the gut epithelium at that stage. $(B)$ Cells overexpressing ngn3 from the stomach to the yolk stalk start expressing glucagon, as shown in brown by immunohistochemistry in the stomach $(C)$ and yolk stalk $(F)$. (D) A section adjacent to $C$ shows that insulin is not present in these cells. $(E)$ A section adjacent to $F$ shows the location of ngn3-positive cells, labeled in blue after in situ hybridization. Most glucagon-positive cells emigrate from the epithelium after $48 \mathrm{~h}$ and aggregate into islets $(B, C, F)$ of about $10-100$ cells. Glucagon immunostaining alone (green; $G, I$ ) or overlayed with somatostatin immunostaining $\left(\mathrm{red}_{;} H, J\right)$ of typical islets close to the epithelium in the region of the jejunum. Somatostatin-positive cells are distinct from glucagon-positive cells and are located at the periphery of the islet. Bars, $50 \mu \mathrm{m}$.

cagon cells differentiate, but the expansion of the bud is limited and it does not branch properly. In addition, the ability of Pdx-1 to bind the insulin and Glut2 promoters and transactivate these genes suggests that it is required for the function of $\beta$ cells. Accordingly, a conditional knockout that allows pancreas formation, but affects late $P d x-1$ expression in $\beta$ cells (Ahlgren et al. 1998) results in defective insulin secretion and a diabetic condition. All together, these data are consistent with the idea that $P d x-1$ is a selector gene for the pancreatic domain.

The results reported here suggest that $P d x-1$ plays an important role in pancreatic bud formation by allowing cells to invade the mesenchyme. We show that $P d x-1$ induces cell budding from the epithelium, a result which appears contradictory to the observation that pancreatic buds form when $P d x-1$ is inactivated. Pancreas bud formation is likely to involve numerous steps, including asymmetric cell divisions, invasion of the mesenchyme, digestion of the extracellular matrix and reinforcement of cell-cell adhesions to form an epithelium and islet. The process of cell migration that we observe does not completely mimic what happens during bud formation. Indeed, individual cells ectopically expressing $P d x-1$ can migrate out of the epithelium whereas during pancreas organogenesis, cells of the bud remain connected to one another and to the gut tube. This difference may be due to the mosaic expression of $P d x-1$ by electroporation where single isolated cells can express $P d x-1$ without having similar neighbors with which to interact.

In vivo, although $P d x-1$ is normally expressed in the duodenum, duodenal cells never form buds. $P d x-1$ expression levels are always higher in the pancreatic bud, and we have observed that only cells that express high levels of $P d x-1$ emigrate from the epithelium in our misexpression experiments.

\section{Pdx-1 maintains the boundaries of the duodeno- pancreatic domain}

The ability of $P d x-1$ to turn off the expression of transcription factors of adjacent regions may reveal a role in maintaining boundaries between the duodenum and neighboring regions of the jejunum, stomach and bile duct. The expression of markers of these regions, Sox2, $C d x A, C d x C$, and Hex may be prevented in the cells of the duodenum and pancreas by $P d x-1$ expression. $C d x A$ and $C d x C$ do not reciprocally turn off $P d x-1$ expression.

\section{Pdx-1, MNR2, and Hlxb-9 cooperate to prevent Shh expression in the pancreas}

In normal development, it is important to ensure that Shh is not expressed in the pancreas as Shh converts pancreatic mesenchyme into intestinal mesenchyme and impairs islet formation and branching (Apelqvist et al. 1997). Here, we show that $P d x-1$ is sufficient to turn off Shh expression. Shh and $P d x-1$ may down-regulate each other's expression, forming a regulatory loop. Indeed the ability of activin- $\beta B$ to induce $P d x-1$ in isolated pancreatic endoderm is prevented by addition of bioactive Shh peptide (Hebrok et al. 1998).

In our misexpression studies, $P d x-1, M N R 2$, and $H l x b-9$ share the ability to turn off Shh expression. We propose that, in vivo, these three genes, and possibly others, have additive actions on the Shh promoter and act to turn off its transcription. Indeed, $P d x-1, M N R 2$, and $H 1 x b-9$ do not belong to the same pathway leading to Shh down-regulation. Although MNR2 up-regulates $H 1 x b-9$, neither of them induces $P d x-1 . P d x-1$ induces $H 1 x b-9$ in a subset of cells, has no effect on MNR2, but 
does turn off $S h$ expression in all cells misexpressing $P d x-1$.

In normal development, neither $H 1 x b-9$ nor $P d x-1$ is sufficient to repress $S h h$. Indeed, Shh and $P d x-1$ are coexpressed in the duodenum. Similarly, Shh and Hlxb-9 are expressed together in the dorsal part of the gut tube. In addition, when $H 1 x b-9$ is inactivated alone, $P d x-1$ expression is absent from the dorsal bud but Shh is still repressed in the presumptive territory of the pancreas (Apelqvist et al. 1997). The pancreas is the only domain were these three genes are expressed together. In our experiments, genes are expressed at a very high level compared with their endogenous level of expression, and this high level of expression may short-cut the requirement for additive negative regulators.

Pdx-1 is not sufficient to elicit endocrine or exocrine cell formation in the gut epithelium

Our study shows that $P d x-1$ does not trigger complete cell differentiation from embryonic endoderm cells. This observation contrasts with the recent observations of Ferber et al. (2000). These authors show that misexpression of Pdx-1 in the liver, by the means of an adenoviral vector, can lead to insulin-producing cell differentiation from liver tissue. Hence, even in the adult, endoderm can be transformed by the sole action of Pdx-1 into insulin cells. Although these authors observe that $30 \%-$ $60 \%$ of hepatocytes express $P d x-1$, only $0.1 \%-1 \%$ exhibit insulin expression. This observation suggests that either a secondary event, not necessarily a consequence of Pdx-1 expression, is required or that only a subpopulation of liver cells is responsive, possibly stem cells. In our experiments, we could have missed insulin staining as the frequency of the event is as low as 1 cell out of 600 in the studies by Ferber et al. (2000). Alternatively, liver cells, but not gut lining cells, could fully differentiate into $\beta$ cells under the influence of $\mathrm{Pdx}-1$. In our chick experiments, the liver does not have many electroporated cells $(<50)$.

Understanding the regulatory networks of transcription factors that lead to differentiation of specific cell types in the pancreas is a tall order. At a minimum, our results argue against $P d x-1$ as a master gene for pancreas organogenesis. Similarly, Pax6 and Is11, alone or in combination with $P d x-1$, are unable to drive complete differentiation of endocrine cells.

ngn3 is sufficient to elicit endocrine cell formation in the gut epithelium

The fact that ngn3 induces glucagon is not surprising. Indeed, Apelqvist et al. (1999) and Schwitzgebel et al. (2000) show that overexpression of ngn3 (or a dominant negative form of Notch3) in the pancreas causes both increased and precocious differentiation of pancreatic glucagon-expressing cells. Similarly, pancreatic cells in which Hes-1, a hairy gene activated by the Notch pathway, is inactivated, precociously differentiate into glu- cagon-cells (Jensen et al. 2000). The novelty of our results is that glucagon cells are induced outside of the pancreas region by ngn 3 and not only where $P d x-1$ is coexpressed as suggested by Schwitzgebel et al. (2000). ngn3 does not induce $P d x-1$ outside of the pancreatic field. This result points to the idea that ngn3 does not require the cooperation of all other pancreas-specific patterning genes to elicit glucagon-producing cell differentiation in the endoderm. Our results also show that ngn 3 is also able to induce the differentiation of another endocrine cell type, $\delta$ cells expressing somatostatin. Neither $\beta$ cells expressing insulin nor PP cells expressing pancreatic polypeptide were induced by ngn3.

The composition of chicken islets is different from that of mice or humans. Instead of $90 \% \beta$ cells, chick islets have a majority of $\alpha$ cells. This situation is unlikely to account for the lack of insulin differentiation in our experiment as somatostatin-producing cells that are less numerous than insulin-producing cells in islets are observed. Moreover, the absence of insulin induction by ngn3 is also observed in the mouse (Apelqvist et al. 1999; Schwitzgebel et al. 2000).

ngn 3 misexpression in the gut tube may trigger ectopic differentiation of pancreatic endocrine cells or precocious differentiation of gut endocrine cell types. ngn3 is expressed at later stages in endoderm regions other than the pancreas, and its inactivation leads to the absence of both pancreatic and enteroendocrine cell differentiation (Gradwohl et al. 2000; G. Gradwohl, pers. comm.). Other genes in the pathway (e.g., hes, NeuroD) are required for endocrine cell differentiation in both the pancreas and gut (Naya et al. 1997; Jensen et al. 2000). However, our experiments demonstrate the ability of ngn3 to trigger cell migration from the gut epithelium, a unique property of endocrine cells of the pancreas. The involvement of bHLH genes in cell delamination from epithelia is not without precedent. ngn2 inactivation prevents the cells of epithelial placodes of the head from delaminating and later on aggregate into sensory ganglia (Fode et al. 1998). In Drosophila, sense organs precursors delaminate shortly after Achaete/Scute gene expression. The Notch/ delta pathway acting upstream of ngns also plays a role in cell migration. Hartenstein et al. (1992) showed that, in the fly, Notch activity is involved in the maintenance of epithelial structures.

ngn3 not only has a general proendocrine function but also plays a role in the specification of pancreatic endocrine cells. This observation is consistent with observations made in the fly that proneural genes can act as neuronal selector genes. Indeed, achaete/scute genes, proneural genes homologous to the vertebrate MASH family, induce external sense organs in the ectoderm whereas atonal, a proneural gene homologous to vertebrate neurogenins, preferentially induces chordotonal organs (Jarman et al. 1993). atonal can repress external sense organ differentiation by repressing the activation of cut (Jarman and Ahmed 1998). In the mouse, specific bHLH genes direct cells to specific neuronal differentiation pathways (Fode et al. 2000). On the other hand, the same gene induces different cell types depending on 
where it is expressed. For instance, atonal can elicit photoreceptor, chordotonal neuron, or olfactory neuron differentiation depending on the imaginal disc it is expressed in (Goulding et al. 2000). In vertebrates, Mash1 elicits GABA-neuron differentiation in the telencephalon (Fode et al. 2000) and noradrenergic differentiation in the hindbrain (Hirsch et al. 1998). Similarly, in our case, two questions concerning endocrine subtype selection arise: (1) Why do certain cells become somatostatin positive and others glucagon positive? (2) Why are $\beta$ cells never induced by ngn 3 even though this gene is required for their differentiation?

ngn3 is normally expressed transiently in individual cells of the pancreas and gut epithelium, but its overall expression is maintained over a long time frame. The gene is turned off when cells complete their differentiation. However, our experiments show that differentiation into $\alpha$ cells can proceed in the presence of ngn3. ngn3 may induce glucagon- and somatostatin-producing cell differentiation by default and additional modifiers of endocrine identity may be activated independently to generate other endocrine cell types. It is unlikely that we are missing a factor that is specific to the pancreas region as, even in the pancreas, electroporated ngn3-positive cells do not differentiate into $\beta$ cells. We show that the most likely candidate, Pax4 (Sosa-Pineda et al. 1997), is not sufficient to elicit the transformation into $\beta$ cells.

The pancreas is an important organ because it is the target of two diseases, diabetes and pancreatic cancer. Although the function of the pancreas in controlling glucose homeostasis is compensated by insulin injection in diabetic patients, the physiological effects are inexact and too variable. Among approaches that are currently being explored to find a cure for diabetes are the isolation and propagation of embryonic or adult stem cells that can be engineered to produce endocrine hormones and then transplanted to patients. Our approach shows that simple gene combinations may be sufficient to generate pancreatic cell types from embryonic endoderm cells. One can envisage introducing these genes in stem cells.

\section{Material and methods}

\section{In ovo electroporation}

Electroporation constructs: pMiwZ (Muramatsu et al. 1996; a gift from T. Muramatsu) contains an RSV promoter driving LacZ expression (Suemori et al. 1990). All other genes are expressed under the control of the CMV LTR and $\beta$-actin promoter of the pCAGGS vector (Niwa et al. 1991; gifts from H. Ogino and J.Miyazaki) or of a modified pCAGGS vector (pCIG, a gift from Sean Megason) in which an internal ribosome entry site (IRES), a nuclear localization signal, and eGFP are expressed downstream of the gene of interest. Full-length chicken $P d x-1$ (Kim et al. 1997b) was expressed either in pCAGGS or pCIG with similar results. Recombinant PCR was used to engineer a construct coding for a mutated $\mathrm{Pdx}-1$ protein unable to bind DNA by changing the leucine between helices 2 and 3 of the homeodomain into a proline. In parallel first rounds, primer 1 (TTGATATCGAATTCGCGG) plus primer 2 (CTCTCGGTC GGGTTTAACATG) and primer 3 (CATGTTAAACCCGACC GAGAG) plus primer 4 (GGAGGCCGCGGTCACGGC) were used, followed by the amplification of mixed purified products by primers 1 and 4 . A cDNA containing the mutated coding sequence was cloned into pCAGGS. Mouse Pax6 and Pax4 coding sequences (Genbank accession no. NM013627) were PCR amplified and cloned into pCAGGS (gifts from Cheng Lai). Mouse is 11 coding sequence (Genbank accession no. AJ132765) was PCR amplified and cloned into pCAGGS. IRES and $P d x-1$ coding sequence in frame were cloned downstream of isll in coexpression studies. $C d x A$ and $C d x C$ (Frumkin et al. 1993; Marom et al. 1997; gifts from Abraham Fainsod) were cloned into pCAGGS. Chicken Hlxb-9 and MNR2 (Tanabe et al. 1998; a gift from Tom Jessel) were cloned into pCIG. Mouse ngn3 coding sequence (Genbank accession no. U76208) was PCR amplified and cloned into pCAGGS. Protein synthesis was checked by immunostaining for Pdx-1, Hlxb-9, MNR2 and isl-1. For other constructs, we checked for RNA transcripts.

Fertilized White Leghorn chicken eggs (SPAFAS, Preston, CT) were incubated at $38^{\circ} \mathrm{C}$ in a humidified atmosphere. Electroporation was performed on embryos between the 18- and 25somite stage (18-25 ss; i.e., stage $13-15 \mathrm{HH})$, corresponding to about $54 \mathrm{~h}$ of incubation at $38^{\circ} \mathrm{C}$. The technique was adapted from neural tube electroporations described by Muramatsu et al. (1996). A hole was made in the shell on the side of the air chamber and a window was then cut on top of the egg. A solution of $2 \mu \mathrm{g} / \mu \mathrm{L}$ DNA in $1 \mathrm{x} \times \mathrm{BS}, 1 \mathrm{mM} \mathrm{MgCl}, 3 \mathrm{mg} / \mathrm{mL}$ carboxymethylcellulose, and $50 \mu \mathrm{g} / \mathrm{mL}$ Nile Blue Sulfate, was injected in the blastocoel (Fig. 2). A few drops of $1 \times$ PBS were added to the top of the embryo to establish an even electrical current. A negative electrode was inserted below the embryo parallel to its anterior-posterior axis, and a positive electrode was held by a micromanipulator parallel to and above the embryo but touching the PBS (Fig. 2). Three square pulses of 17 volts and $50 \mathrm{~ms}$ each were applied to the embryo (BTX T-820 square wave electroporator). After electroporation, eggs were resealed with tape and placed at $38^{\circ} \mathrm{C}$ for 24 to $96 \mathrm{~h}$. Fixation was done in $4 \%$ paraformaldehyde/PBS for $\mathrm{LacZ}$ stainings and frozen sections or in a solution of 6 parts $100 \% \mathrm{EtOH}, 3$ parts $37 \%$ formaldehyde, and 1 part glacial acetic acid for in situ hybridization and immunocytochemistry on paraffin sections.

All observations were corroborated on at least three, but usually five, embryos. None of the embryos sampled led to opposite conclusions.

\section{In situ hybridization}

Paraffin sections $(6 \mu \mathrm{m})$ were collected on glass slides (Superfrost Plus) and hybridized with digoxygenin and/or fluoresceinlabeled probes as described previously (Wilting et al. 1997). Briefly, sections were dewaxed, treated with $1 \mu \mathrm{g} / \mathrm{mL}$ Proteinase $\mathrm{K}$ for $7 \mathrm{~min}$, and postfixed in $4 \%$ paraformaldehyde. Hybridization mix contained $1 \mu \mathrm{m} / \mathrm{mL}$ of probe, and hybridization was done overnight at $70^{\circ} \mathrm{C}$. When two probes were used, fluorescein and digoxygenin-labeled probes were added at the same time. Sections were washed in maleic acid buffer and blocked with $20 \%$ lamb serum/2\%Blocking Reagent (Boehringer Mannheim). Slides were washed again and developed with NBT and BCIP. The fluorescein-labeled probe, always corresponding to the gene that was overexpressed, was amplified in a second step after inactivating anti-digoxygenin antibodies with glycine buffer $(\mathrm{pH} 2.2)$ and subsequently incubating overnight with anti-fluorescein-alkaline phosphatase antibody (Boehringer Mannheim), 1:5000. Slides were washed again and developed with INT and BCIP (Boehringer Mannheim).

In situ hybridization probes were the following: for $c P d x-1$ (Kim et al. 1997b), CdxA, CdxC (Frumkin et al. 1993) (Marom et al. 1997; a gift from Dr. Fainsod), cHex (Crompton et al. 1992) (a 
gift from Dr. Goodwin), cShh (Roberts et al. 1995; a gift from Cliff Tabin), NeuroD-L (Perez et al., 1997; a gift from David Anderson) MNR-2 (Tanabe et al. 1998), and nkx2.2, Pax6 and isl1 (gifts from Tom Jessel) the probes corresponded to the fulllength cDNA. For cHlxb-9 (Tanabe et al. 1998; a gift from Tom Jessel), the sequence $5^{\prime}$ of the homeobox was used to guarantee the absence of cross-hybridization with MNR2 in the homeobox region. For Sox2, the sequence encompassing nucleotides 273926 (Genbank accession no. U12532) was cloned by PCR.

\section{Immunohistochemistry}

Guinea pig-anti-insulin (1:200, Dako), Guinea pig-anti-glucagon (1:200, Linco), Rabbit-anti-somatostatin (1:200, Dako), Rabbitanti-pancreatic polypeptide (1:200, Dako) and anti-carboxypeptidaseA (1:200; Chemicon) polyclonal antibodies were incubated overnight on dewaxed paraffin sections, after blocking endogenous peroxidases when diaminobenzidine was used. Biotin-, Peroxidase-, fluorescein- or Cy3-conjugated secondary antibodies (Jackson Laboratories) were diluted 1:100.

Anti-PDX-1 (a gift from Chris Wright), and anti-MNR2/ Hlxb-9 and anti-ISL1 (Developmental Studies Hybridoma Bank) antibodies were diluted 1:1000 for the first one and 1:100 for others and used on $10-\mu \mathrm{m}$ frozen sections.

$L a c Z$ was developed on whole embryos using the Histomark kit (Kirkegaard \& Perry).

\section{Acknowledgments}

We thank Drs. Abraham Fainsod, Goodwin, Matthias Hebrok, Tom Jessel, Seung Kim, Cheng Lai, Sean Megason, J. Miyazaki, Muramatsu, H. Ogino, Cliff Tabin, David Anderson and Chris Wright for sharing reagents. A.G.B. was supported by grants from the French Association for Cancer Research (ARC) and the Human Frontier Science Program (HFSP). D.A.M. is an investigator of the Howard Hughes Medical Institute. This work was supported in part by the Juvenile Diabetes Research Foundation. We are indebted to members of the Melton lab for helpful discussions, to Renata Hellmiss for her help with figures and to Francois Guillemot and Gérard Gradwohl for their comments on the manuscript.

The publication costs of this article were defrayed in part by payment of page charges. This article must therefore be hereby marked "advertisement" in accordance with 18 USC section 1734 solely to indicate this fact.

\section{References}

Ahlgren, U., Pfaff, S.L., Jessell, T.M., Edlund, T., and Edlund, H. 1997. Independent requirement for ISL1 in formation of pancreatic mesenchyme and islet cells. Nature 385: 257-260.

Ahlgren, U., Jonsson, J., Jonsson, L., Simu, K., and Edlund, H. 1998. $\beta$-Cell-specific inactivation of the mouse Ipf1/Pdx 1 gene results in loss of the beta-cell phenotype and maturity onset diabetes. Genes Dev. 12: 1763-1768.

Alpert, S., Hanahan, D., and Teitelman, G. 1988. Hybrid insulin genes reveal a developmental lineage for pancreatic endocrine cells and imply a relationship with neurons. Cell 53: 295-308.

Apelqvist, A., Ahlgren, U., and Edlund, H. 1997. Sonic hedgehog directs specialised mesoderm differentiation in the intestine and pancreas. Curr. Biol. 7: 801-804.

Apelqvist, A., Li, H., Sommer, L., Beatus, P., Anderson, D.J., Honjo, T., Hrabe de Angelis, M., Lendahl, U., and Edlund, H. 1999. Notch signalling controls pancreatic cell differentia- tion. Nature 400: 877-881.

Beaupain, D. and Dieterlen-Lièvre, F. 1974. Étude immunocytologique de la différenciation du pancréas endocrine chez l'embryon de poulet. II. Glucagon. Gen. Comp. Endocrinol. 23: 421-431.

Crompton, M.R., Bartlett, T.J., MacGregor, A.D., Manfioletti, G., Buratti, E., Giancotti, V., and Goodwin, G.H. 1992. Identification of a novel vertebrate homeobox gene expressed in haematopoietic cells. Nucleic Acids Res. 20: 5661-5667.

Echelard, Y., Epstein, D.J., St-Jacques, B., Shen, L., Mohler, J., McMahon, J.A., and McMahon, A.P. 1993. Sonic hedgehog, a member of a family of putative signaling molecules, is implicated in the regulation of CNS polarity. Cell 75: 14171430.

Edlund, H. 1998. Transcribing pancreas. Diabetes 47: 18171823.

Ferber, S., Halkin, A., Cohen, H., Ber, I., Einav, Y., Goldberg, I., Barshack, I., Seijffers, R., Kopolovic, J., Kaiser, N., and Karasik, A. 2000. Pancreatic and duodenal homeobox gene 1 induces expression of insulin genes in liver and ameliorates streptozotocin-induced hyperglycemia. Nat. Med. 6: 568572.

Fode, C., Gradwohl, G., Morin, X., Dierich, A., LeMeur, M., Goridis, C., and Guillemot, F. 1998. The bHLH protein NEUROGENIN 2 is a determination factor for epibranchial placode-derived sensory neurons. Neuron 20: 483-494.

Fode, C., Ma, Q., Casarosa, S., Ang, S.L., Anderson, D.J., and Guillemot, F. 2000. A role for neural determination genes in specifying the dorsoventral identity of telencephalic neurons. Genes Dev. 14: 67-80.

Frumkin, A., Haffner, R., Shapira, E., Tarcic, N., Gruenbaum, Y., and Fainsod, A. 1993. The chicken CdxA homeobox gene and axial positioning during gastrulation. Development 118: $553-562$.

Goulding, S.E., White, N.M., and Jarman, A.P. 2000. cato encodes a basic helix-loop-helix transcription factor implicated in the correct differentiation of Drosophila sense organs. Dev. Biol. 221:120-131.

Gradwohl, G., Dierich, A., LeMeur, M., and Guillemot, F. 2000. neurogenin 3 is required for the development of the four endocrine cell lineages of the pancreas. Proc. Natl. Acad. Sci. 97: $1607-1611$.

Grapin-Botton, A. and Melton, D.A. 2000. Endoderm development: from patterning to organogenesis. Trends Genet. 16: $124-130$.

Hamburger, V. and Hamilton, H.L. 1951. A series of normal stages in the development of the chick embryo. J. Morphol. 88: 49-92.

Harrison, K.A., Thaler, J., Pfaff, S.L., Gu, H., and Kehrl, J.H. 1999. Pancreas dorsal lobe agenesis and abnormal islets of Langerhans in Hlxb9-deficient mice. Nat. Genet. 23: 71-75.

Hartenstein, A.Y., Rugendorff, A., Tepass, U., and Hartenstein, V. 1992. The function of the neurogenic genes during epithelial development in the Drosophila embryo. Development 116: 1203-1220.

Hebrok, M., Kim, S.K., and Melton, D.A. 1998. Notochord repression of endodermal Sonic hedgehog permits pancreas development. Genes Dev. 12: 1705-1713.

Hirsch, M.R., Tiveron, M.C., Guillemot, F., Brunet, J.F., and Goridis, C. 1998. Control of noradrenergic differentiation and Phox2a expression by MASH1 in the central and peripheral nervous system. Development 125: 599-608.

Jarman, A.P. and Ahmed, I. 1998. The specificity of proneural genes in determining Drosophila sense organ identity. Mech. Dev. 76: 117-125.

Jarman, A.P., Grau, Y., Jan, L.Y., and Jan, Y.N. 1993. atonal is a 
proneural gene that directs chordotonal organ formation in the Drosophila peripheral nervous system. Cell 73: 13071321.

Jensen, J., Pedersen, E.E., Galante, P., Hald, J., Heller, R.S., Ishibashi, M., Kageyama, R., Guillemot, F., Serup, P., and Madsen, O.D. 2000. Control of endodermal endocrine development by Hes-1. Nat. Genet. 24: 36-44.

Jonsson, J., Carlsson, L., Edlund, T., and Edlund, H. 1994. Insulin-promoter-factor 1 is required for pancreas development in mice. Nature 371: 606-609.

Kim, S.K., Hebrok, M., and Melton, D.A. 1997a. Notochord to endoderm signaling is required for pancreas development. Development 124: 4243-4252.

1997b. Pancreas development in the chick embryo. Cold Spring Harbor Symp. Quant. Biol. 62: 377-383.

Krapp, A., Knofler, M., Ledermann, B., Burki, K., Berney, C., Zoerkler, N., Hagenbuchle, O., and Wellauer, P.K. 1998. The bHLH protein PTF1-p48 is essential for the formation of the exocrine and the correct spatial organization of the endocrine pancreas. Genes Dev. 12: 3752-3763.

Li, H., Arber, S., Jessell, T.M., and Edlund, H. 1999. Selective agenesis of the dorsal pancreas in mice lacking homeobox gene Hlxb9. Nat. Genet. 23: 67-70.

Lumsden, A. and Krumlauf, R. 1996. Patterning the vertebrate neuraxis. Science 274: 1109-1115.

Marom, K., Shapira, E., and Fainsod, A. 1997. The chicken caudal genes establish an anterior-posterior gradient by partially overlapping temporal and spatial patterns of expression. Mech. Dev. 64: 41-52.

McGinnis, W. and Krumlauf, R. 1992. Homeobox genes and axial patterning. Cell 68: 283-302.

Muramatsu, T., Mizutani, Y., and Okumura, J. 1996. Live detection of the firefly luciferase gene expression by bioluminescence in incubating chicken embryos. Animal Science Technology (jpn) 67: 906-909.

Naya, F.J., Huang, H.P., Qiu, Y., Mutoh, H., DeMayo, F.J., Leiter, A.B., and Tsai, M.J. 1997. Diabetes, defective pancreatic morphogenesis, and abnormal enteroendocrine differentiation in BETA2/neuroD-deficient mice. Genes Dev. 11: 2323-2334.

Niwa, H., Yamamura, K., and Miyazaki, J. 1991. Efficient selection for high-expression transfectants with a novel eukaryotic vector. Gene 108: 193-199.

Offield, M.F., Jetton, T.L., Labosky, P.A., Ray, M., Stein, R.W., Magnuson, M.A., Hogan, B.L., and Wright, C.V. 1996. PDX-1 is required for pancreatic outgrowth and differentiation of the rostral duodenum. Development 122: 983-995.

Perez, S.E., Rebelo, S., and Anderson, D.J. 1999. Early specification of sensory neuron fate revealed by expression and function of neurogenins in the chick embryo. Development 126: 1715-1728.

Roberts, D.J., Johnson, R.L., Burke, A.C., Nelson, C.E., Morgan, B.A., and Tabin, C. 1995. Sonic hedgehog is an endodermal signal inducing Bmp-4 and Hox genes during induction and regionalization of the chick hindgut. Development 121: 3163-3174.

Sander, M., Neubuser, A., Kalamaras, J., Ee, H.C., Martin, G.R., and German, M.S. 1997. Genetic analysis reveals that PAX6 is required for normal transcription of pancreatic hormone genes and islet development. Genes Dev. 11: 1662-1673.

Schwitzgebel, V.M., Scheel, D.W., Conners, J.R., Kalamaras, J., Lee, J.E., Anderson, D.J., Sussel, L., Johnson, J.D., and German, M.S. 2000. Expression of neurogenin3 reveals an islet cell precursor population in the pancreas. Development 127: 3533-3542.

Sosa-Pineda, B., Chowdhury, K., Torres, M., Oliver, G., and
Gruss, P. 1997. The Pax4 gene is essential for differentiation of insulin-producing $\beta$ cells in the mammalian pancreas. $\mathrm{Na}$ ture 386: 399-402.

St-Onge, L., Sosa-Pineda, B., Chowdhury, K., Mansouri, A., and Gruss, P. 1997. Pax6 is required for differentiation of glucagon-producing $\alpha$-cells in mouse pancreas. Nature 387: 406409.

Suemori, H., Kadodawa, Y., Goto, K., Araki, I., Kondoh, H., and Nakatsuji, N. 1990. A mouse embryonic stem cell line showing pluripotency of differentiation in early embryos and ubiquitous $\beta$-galactosidase expression. Cell Differ. Dev. 29: $181-186$.

Sumiya, M. and Mizuno, T. 1987. Étude immunohistologique de l'expression de glucagon dans l'endoderme pancréatique dorsal chez l'embryon précoce de poulet. C.R. Soc. Biol. 181: 718-721.

Sussel, L., Kalamaras, J., Hartigan-O'Connor, D.J., Meneses, J.J., Pedersen, R.A., Rubenstein, J.L., and German, M.S. 1998. Mice lacking the homeodomain transcription factor Nkx2.2 have diabetes due to arrested differentiation of pancreatic $\beta$ cells. Development 125: 2213-2221.

Tanabe, Y., William, C., and Jessell, T.M. 1998. Specification of motor neuron identity by the MNR2 homeodomain protein. Cell 95: 67-80.

Wilting, J., Eichmann, A., and Christ, B. 1997. Expression of the avian VEGF receptor homologues Quek1 and Quek2 in blood-vascular and lymphatic endothelial and non-endothelial cells during quail embryonic development. Cell Tissue Res. 288: 207-223. 


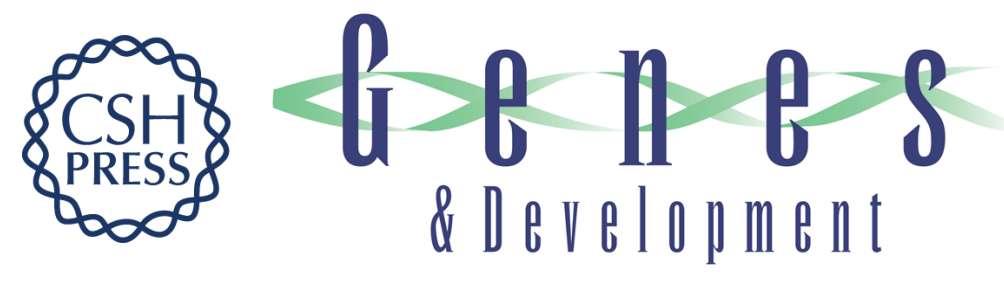

\section{Key events of pancreas formation are triggered in gut endoderm by ectopic expression of pancreatic regulatory genes}

Anne Grapin-Botton, Amit R. Majithia and Douglas A. Melton

Genes Dev. 2001, 15:

Access the most recent version at doi:10.1101/gad.846001

References This article cites 46 articles, 19 of which can be accessed free at: http://genesdev.cshlp.org/content/15/4/444.full.htmI\#ref-list-1

License

Email Alerting

Receive free email alerts when new articles cite this article - sign up in the box at the top Service right corner of the article or click here.

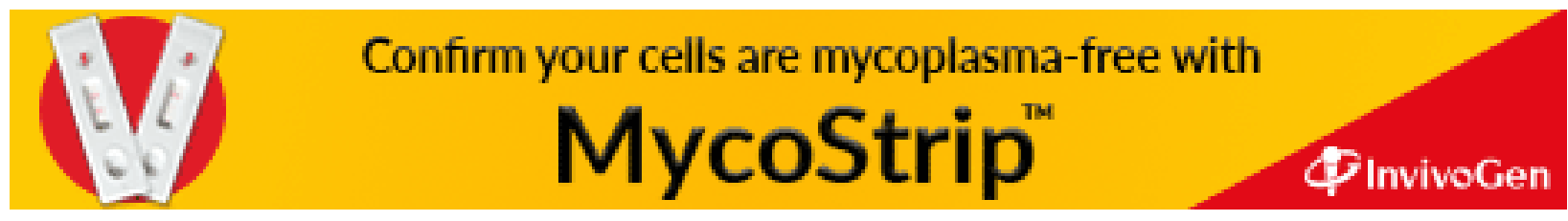

